Research Article

\title{
Electrochemical Properties and Ex Situ Study of Sodium Intercalation Cathode P2/P3-NaNi $\mathbf{1}_{1 / 3} \mathrm{Mn}_{1 / 3} \mathrm{Co}_{1 / 3} \mathrm{O}_{2}$
}

\author{
Minh Le Nguyen, ${ }^{1,2}$ Hoang Van Nguyen $\mathbb{D}^{1,2,3}$ Man Van Tran ${ }^{1}{ }^{1,2,3}$ \\ and Phung My Loan Le $\mathbb{i D}^{1,2,3}$ \\ ${ }^{1}$ Applied Physical Chemistry Laboratory (APCLAB), Faculty of Chemistry, VNUHCM-University of Science, \\ Ho Chi Minh City, Vietnam \\ ${ }^{2}$ Department of Physical Chemistry, Faculty of Chemistry, VNUHCM-University of Science, Ho Chi Minh City, Vietnam \\ ${ }^{3}$ Vietnam National University Ho Chi Minh City (VNU-HCM), Ho Chi Minh City, Vietnam
}

Correspondence should be addressed to Phung My Loan Le; lmlphung@hcmus.edu.vn

Received 21 June 2021; Accepted 17 September 2021; Published 7 October 2021

Academic Editor: Sylvain Franger

Copyright (c) 2021 Minh Le Nguyen et al. This is an open access article distributed under the Creative Commons Attribution License, which permits unrestricted use, distribution, and reproduction in any medium, provided the original work is properly cited.

\begin{abstract}
In recent work, $\mathrm{P} 2 / \mathrm{P} 3-\mathrm{NaNi}_{1 / 3} \mathrm{Mn}_{1 / 3} \mathrm{Co}_{1 / 3} \mathrm{O}_{2}$ (NaNMC) was obtained by the sol-gel process followed by calcination of the precursor at $900^{\circ} \mathrm{C}$ for $12 \mathrm{~h}$. The electrochemical properties of NaNMC were investigated in the voltage range of $2.0-4.0 \mathrm{~V}$. The material exhibited an initial discharge capacity of $107 \mathrm{mAh} \cdot \mathrm{g}^{-1}$ and good capacity retention of $82.2 \%$ after $100 \mathrm{cycles}$. Ex situ XRD performance showed that the P3-phase transformed from the P3- to O1-phase and vice versa, while the P2-phase remained stable during the sodium intercalation. The kinetic of sodium intercalation of NaNMC upon reversible $\mathrm{Na}^{+}$insertion/deinsertion was evaluated via a Galvanostatic Intermittence Titration Technique (GITT) and Electrochemical impedance spectroscopy (EIS). The diffusion coefficients of $\mathrm{Na}^{+}$ion deduced from the GITT curve have a broad distribution ranging from $10^{-10}$ to $10^{-11} \mathrm{~cm}^{2} \cdot \mathrm{s}^{-1}$ for the charging/discharging process. Besides, the evolution of diffusion coefficient and charge transfer resistance is consistent with the complex phase transition generally observed in sodium layered oxides.
\end{abstract}

\section{Introduction}

Lithium-ion batteries (LIBs) are currently the dominant energy storage technology [1] investigated among various electrochemical power sources since the 1970-1980s and successfully introduced in the market by SONY in 1991 [2]. LIBs have been extensively used for various portable electronic devices and will be extended for transportation vehicles [3]. However, the limited lithium resource and the high cost of LIB were obstacles, especially when large-scale renewable energy storage became popular. Thus, many efforts have been devoted to developing rechargeable batteries using earthabundant elements. Sodium ion batteries (SIBs) have been regained extensive attention as a potential alternative to LIBs owing to the cost effectiveness and earth abundance of sodium resource (more than 1000 times higher than that of lithium) [4]. Given the similarity of the chemistry and working mechanism of SIB and LIB, the comprehensive knowledge about LIBs can be applied to make SIBs competitive to lithium-ion batteries in cell market $[4,5]$.

In SIBs, cathode materials offer $\mathrm{Na}^{+}$ions and high potential redox couples, which play a crucial role in determining the operating voltages and reversible capacity of the battery. In cathode material, the layered transition metal oxide class offers promising candidates in SIBs owing to their highly reversible capacity and the facile synthesis [6-11]. The layered structure is built by sheets of edge-shape $\mathrm{MO}_{6}$ octahedra, wherein alkali ions are located between $\mathrm{MO}_{6}$ sheets. Sodium cathodes with layered structure could be divided into two main groups, the $\mathrm{O} 3$ type and $\mathrm{P} 2$ type, as Delmas notation in which sodium ions occupied octahedral and prismatic sites, respectively [12]. O3-type layered cathodes can deliver higher reversible specific capacity and take precedence over P2 in full-cell assembly $[7,8]$. 
Among layered transition metal oxides, the $\mathrm{NaNi}_{1 / 3} \mathrm{Mn}_{1 / 3} \mathrm{Co}_{1 / 3} \mathrm{O}_{2}$ phase (hereafter denoted as NaNMC) appears as an attractive candidate cathode material for $\mathrm{Na}$ ion batteries. NaNMC, as an isotope layered structure of $\alpha-\mathrm{NaFeO}_{2}$, is a counterpart of $\mathrm{LiNi}_{1 / 3} \mathrm{Mn}_{1 / 3} \mathrm{Co}_{1 / 3} \mathrm{O}_{2}$. The material is a tertiary oxide, but the $\mathrm{Ni}^{4+} / \mathrm{Ni}^{2+}$ couple is the main redox couple contributing to the overall capacity. $\mathrm{Co}^{3+}$ helps to enlarge the working voltage of NaNMC up to $4.0 \mathrm{~V}$, while $\mathrm{Mn}^{4+}$ maintains the structural stability of NaNMC $[7,8]$.

The material was synthesized by several routes such as solid-state reaction [9, 13-15], medium-based routes such as sol-gel [16-19], and coprecipitation [8, 20-22] followed by solid-state calcination. In sodium half-cell, the material exhibited stair-like potential variation within the voltage range of 2.0-3.75 $\mathrm{V}$ due to several biphasic and monophasic transformations originated from the gliding of the slab after sodium extraction/insertion. Because of its complex composition, multiple-phase materials which contained at least two phases or triple phases could be obtained by different calcination procedures $[10-12,23]$. Xu et al. reported that triple-phase $\mathrm{P} 2 / \mathrm{O} 1 / \mathrm{O} 3$ and biphase $\mathrm{P} 2 / \mathrm{O} 3$ - and $\mathrm{P} 2 / \mathrm{P} 3-$ NaNMC were gained by varying the heat treatment [24]. The electrochemical characterization demonstrated that the former triple-phase integration displayed better performance and thermal stability than the others which was correlated with the united interfacial microstrain development during synthesis procedure and cycling. In addition, kinetics of $\mathrm{Na}$ diffusion is one of the key parameters related to the performance of intercalation compounds. Cyclic voltammetry (CV), electrochemical impedance spectroscopy (EIS), and the Galvanostatic Intermittent Titration Technique (GITT) have been common as reliable methods to evaluate and calculate the kinetic parameters. The kinetics of sodium migration in triple-phase P2/O1/O3-NaNMC was investigated previously by our group [25]. It was found that the evolution of diffusion coefficient and charge transfer resistance of an electrode matched to the structure evolution upon $\mathrm{Na}^{+}$ion extraction/insertion. P2/O3-NaNMC was also synthesized, and the electrochemical properties were evaluated [16]. Herein, the double P-type integrated phase was obtained by a simple solid-state reaction of a sol-gel precursor at $900^{\circ} \mathrm{C}$. $\mathrm{P} 2 / \mathrm{P} 3$ biphasic compounds might combine the advantages of the P2-phase and P3-phase to improve both cycling stability and reaction kinetic. We also explore the kinetics of sodium ion diffusion in P2/P3-NaNMC material during the intercalation process through its diffusion coefficient and the evolution of charge transfer resistance related to the redox reaction by the GITT and EIS techniques.

\section{Experimental}

2.1. Preparation of P2/P3-NaNMC Material. The acid citricassisted sol-gel process for precursor synthesis with a nominal stoichiometry was prepared by the process reported elsewhere [17] with suitable adjustment. Firstly, $\mathrm{NaOH}$ (Merck, >99\%), $\mathrm{Ni}\left(\mathrm{NO}_{3}\right)_{2} \cdot 6 \mathrm{H}_{2} \mathrm{O}$ (Sigma-Aldrich, >99\%), $\mathrm{Co}\left(\mathrm{NO}_{3}\right)_{2} \cdot 6 \mathrm{H}_{2} \mathrm{O}$ (Sigma-Aldrich, $>99 \%$ ) and $\mathrm{Mn}(\mathrm{OAc})_{2} \cdot 4 \mathrm{H}_{2} \mathrm{O}$ (Acros, $>99 \%$ ), and chelating agent acid citric in the molar ratio $1.05: 0.33$ : $0.33: 0.33: 2.05$, respectively, were dissolved in distilled water. Acid citric was used as the chelating agent, and the decomposition of metal-citrate complexes assisted uniform distribution and reduced particle size. $\mathrm{NH}_{3}$ 25\% solution (Kanto Chemical) was added to the abovementioned solution to adjust $\mathrm{pH}$ to $6-7$, and the mixture was heated on a hot plate at $80^{\circ} \mathrm{C}$ under constant stirring to facilitate gel formation. The obtained wetted gel was then heated at $400^{\circ} \mathrm{C}$ for 24 hours to yield a homogeneous precursor.

Secondly, the sol-gel precursor was calcined at $900^{\circ} \mathrm{C}$ for 12 hours under air in a tube furnace. After cooling, the sample was directly moved to an argon-filled glovebox (GPCampus, Jacomex) to ground and store to avoid any reaction with moisture and carbon dioxide.

2.2. Material Characterization. The crystalline structure of NaNMC materials was determined by X-ray diffraction performed on D8 Advanced (Bruker). The materials were radiated by a CuK $\alpha$ source $(\lambda=1.5814 \AA)$ in a $2 \theta$ angle range of $10-70^{\circ}$ within $0.02^{\circ}$ step $/ 0.25$ second rate. Morphology characterization was performed on a field-emission Scanning Electron Microscope (SEM) S-4800 (Hitachi, Japan) with the integration of Energy Dispersive X-ray Spectroscopy (EDX).

2.3. Electrochemical Characterization. Cathode preparation and battery assembly was conducted in an argon-filled glovebox to avoid air and moisture contact. The electrode composite including active material, carbon black C65, and poly (vinylidene fluoride-co-hexafluoropropylene) (PVdFHFP) in the weight ratio of $80: 15: 5$ was mixed with $\mathrm{N}$-methyl-2-pyrrolidone (NMP) to make a slurry and then coated on an aluminum foil. The film was dried at $110^{\circ} \mathrm{C}$ on a hot plate for 12 hours and then was punched into electrode pieces with $12 \mathrm{~mm}$ diameters. The mass loading of the electrode is about $2-3 \mathrm{mg} \cdot \mathrm{cm}^{-2}$. Coin-cell CR2032 was used for electrochemical investigation. The cell consists of the cathode and the anode which were the as-prepared NaNMC and sodium metal, respectively, seperated by two Whatman glass fibers as seperator that impregnated by the electrolyte of $1 \mathrm{M} \mathrm{NaClO} 4$ in propylene carbonate (PC) : fluoroethylene carbonate (FEC) $98: 2$ in volume.

Charging/discharging was performed on the MPG-2 (Biologic) apparatus at a rate of $\mathrm{C} / 10$ (1C corresponding to 1 $\mathrm{Na}$ insert into the structure in 10 hours). In the GITT experiment, the cell was charged in a voltage range of $2.0-4.0 \mathrm{~V}$ at a constant current density of $\mathrm{C} / 20$ for an interval time of 30 minutes followed by an open-circuit voltage (OCV) relaxation period of 3 hours. Electrochemical impedance spectroscopy (EIS) was then performed to elicit the impedance properties of the cathode at that state of charge/ discharge. The sequence of charging/relaxation/EIS was continuously repeated until reaching the cutoff voltage and was applied to the next discharge sequence. For the EIS technique, an alternating current of $10 \mathrm{mV}$ was applied to the cell and the frequency varied from $1 \mathrm{MHz}$ to $10 \mathrm{mHz}$ and was conducted on the VSP (Biologic) apparatus. 
Ex situ XRD was performed on the cathode electrode. The half-cell was charged/discharged at a rate of $\mathrm{C} / 25$ to the expected voltage and then disassembled in the glovebox to obtain cathode films. The cathode film was washed many times with dimethyl carbonate (DMC), dried in a hot plate before being characterized by XRD in D8 Advance (Bruker) coupled with $\mathrm{CuK} \alpha$ radiation $(\lambda=1.5814 \AA)$ at a scan rate of $0.02^{\circ} /$ step $/ 0.25$ second.

\section{Results and Discussion}

3.1. Crystalline Structure and Morphology. The layered structure is formed by a reaction between the sodium precursors and the transition metal precursor whereas the hexagonally arranged oxygen atoms are tightly packed, and then, sodium ions and transition metal ions alternately fill in octahedral holes between adjacent layers. The phase composition of the material was analyzed from the XRD result. Figure 1 presents the XRD results of the as-prepared NaNMC that displays two sets of peaks matched to P2-type and $\mathrm{P} 3$-type layered structure with the $\mathrm{P}_{3} / \mathrm{mmc}$ space group (PDF No: 00-054-0894) and R3m space group (PDF No: 00054-0839), respectively. The mismatch between the peak of the two phases and the corresponding peaks of the standard is due to the difference in lattice parameters. The two phases have $\mathrm{Na}^{+}$ions in prismatic coordination with oxygen atoms between two adjacent layers but differ from stacking configuration of layers [12]. Thus, the synthesized sample has two phases integrating $\mathrm{P} 2 / \mathrm{P} 3$ that are all layered structure. Besides, the additional peak marked as * located at about $63^{\circ}$ of $\mathrm{NiO}$ impurity was also seen. The Rietveld method was used to estimate the distribution of phases resulting in the value of $55.56 \%$ and $44.44 \%$ for the P2- and P3-phase, respectively. The high percentage of the P2-phase could be contributed from its thermodynamically stable phase, so that preferably forms at high temperature [26]. The lattice parameters are also calculated: $a=2.8401 \AA$ and $c=11.0126 \AA$ for the P2-phase and $a=2.8455 \AA$ and $c=16.6 .019 \AA$ for the P3-phase.

SEM images of the synthesized sample (Figures 2(a)2(c)) show irregular polygonal particles with the size of a few micrometers made up of the aggregation of flaky particles with smaller dimensions. Due to the high-temperature treatment, the size distribution is quite large. These submicrometer particles are agglomerated into large secondary particles of several micrometers. EDX analysis was carried out on the NaNMC sample as shown in Figures 2(d)-2(j). The composition deduced from the EDX analysis is $\mathrm{Na}_{1.03} \mathrm{Mn}_{0.35} \mathrm{Ni}_{0.35} \mathrm{Co}_{0.30} \mathrm{O}_{2.05}$, which is highly in agreement with the nominal desired NaNMC composition. EDX mapping results also indicate good distribution of elements in the material (Table 1).

3.2. Electrochemical Properties. The electrochemical characterization of NaNMC in sodium half-cell is presented in the following. Figure 3 presents the initial three cycles in the voltage range of $2.0-4.0 \mathrm{~V}$ at the scan rate of $100 \mu \mathrm{V} \cdot \mathrm{s}^{-1}$. On the CV curve, four couple peaks located at 2.97/2.40, 3.19/
$3.11,3.45 / 3.38$, and $3.74 / 3.63 \mathrm{~V}$ are associated with the active redox couples of $\mathrm{Ni}^{2+} / \mathrm{Ni}^{3+} / \mathrm{Ni}^{4+}$ during the sodium insertion/deinsertion [27]. The peak position and shape of four redox pairs demonstrated the similarity in the redox mechanism of NaNMC reported previously [28] including several biphasic and monophasic transformations.

The voltage profile of P2/P3-NaNMC in Figure 4(a) shows stepwise curves indicating $\mathrm{Na}$ intercalate-driven structural transition typical for NaNMC material. Besides the high reversible nature of the $\mathrm{Na}^{+}$ion intercalation/ deintercalation process, the structure is very stable as well because the shape of the curve remains at the $100^{\text {th }}$ cycle despite the unexpected capacity decreasing. The initial discharge capacity of $107 \mathrm{mAh} \cdot \mathrm{g}^{-1}$ was obtained for doublephase P2/P3-NaNMC in accordance with $0.45 \mathrm{Na}^{+}$ions inserted into the cathode structure in the voltage range 2.0-4.0 V. After 100 cycles, the discharge capacity decreased to $88 \mathrm{mAh} \cdot \mathrm{g}^{-1}$ with $82.2 \%$ retention from the initial capacity (Figure 4(b)). Indeed, the Coulombic efficiency of P2/P3NaNMC is close to $100 \%$. It is noticeable that the P3/P2NaNMC displays higher capacity than each individual phase [18] and reveals the beneficial role of the two-phase intergrowth on improving the performance of NaNMC material. P3/P2-integrated $\mathrm{Na}_{0.62} \mathrm{Mn}_{0.66} \mathrm{Ni}_{0.17} \mathrm{Co}_{0.17} \mathrm{O}_{2}$ [15] also has demonstrated an enhancement in capacity and cycling stability of the P3-phase. In addition, Chen et al. [29] reported that $\mathrm{P} 2 / \mathrm{P} 3-\mathrm{Na}_{0.66} \mathrm{Co}_{0.5} \mathrm{Mn}_{0.5} \mathrm{O}_{2}$ reduced charge transfer resistance than the single $\mathrm{P} 3$-phase material which indicates easier (de)intercalation for $\mathrm{Na}^{+}$. However, the gradual decrease of capacity is still the drawback of the binary-phasic P2/P3-NaNMC despite the capacity retention being higher than that in a previous study due to the lower charge cutoff voltage [24].

Figures 4(c) and 4(d) show the voltage profiles and rate capability, respectively, of the $\mathrm{P} 2 / \mathrm{P} 3-\mathrm{NaNMC}$ electrode in the increase of current density from $\mathrm{C} / 10$ to $2^{\circ} \mathrm{C}$. At the current density of $\mathrm{C} / 10$, the specific capacity is about $100 \mathrm{mAh} \cdot \mathrm{g}^{-1}$. The capacity decreases when the higher current density is applied. At the high current density of $1^{\circ} \mathrm{C}$, the material retains $78 \%$ of the capacity obtained at rate $\mathrm{C} / 10$ $\left(78 \mathrm{mAh} \cdot \mathrm{g}^{-1}\right)$, which is comparable to the O3-NaNMC reported previously [17]. The capacity gained at the highest rate of $2^{\circ} \mathrm{C}$ is $63 \mathrm{mAh} \cdot \mathrm{g}^{-1}$. When the current density switches to $\mathrm{C} / 10$, the electrode displays a full recovery of discharge capacity.

\subsection{Structural Evolution in the Charge/Discharge Process.} Ex situ XRD was conducted to investigate the reaction of the $\mathrm{Na}^{+}$insertion mechanism and the structural evaluation of the NaNMC cathode. Figure 5 shows the ex situ XRD patterns collected at different positions on the first charge.

The XRD pattern of the pristine NaNMC electrode exhibiting the coexistence of the P2- and P3-phase is revealed in Section 3.1. From the initial state to $3.5 \mathrm{~V}$, the changes of those peaks are only the location excursion due to lattice parameter change demonstrating sodium extraction in the solid solution region. At $3.0 \mathrm{~V}$, the split of peak located at $16^{\circ}$ could be the result from the separation of each 

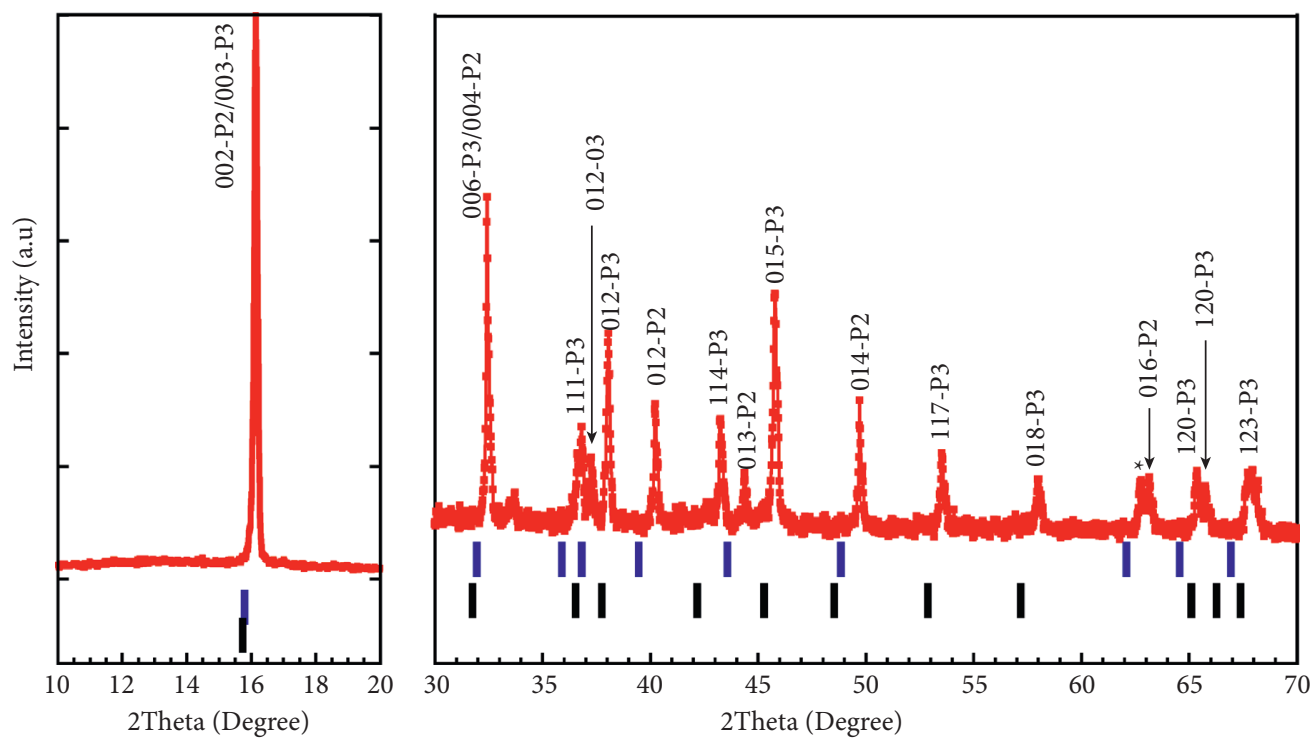

* $\mathrm{NiO}$

I 2 -phase (PDF No: 00-054-0894)

I P3-phase (PDF No: 00-054-0839)

FIgURE 1: X-ray diffraction pattern of the synthesized NaNMC.

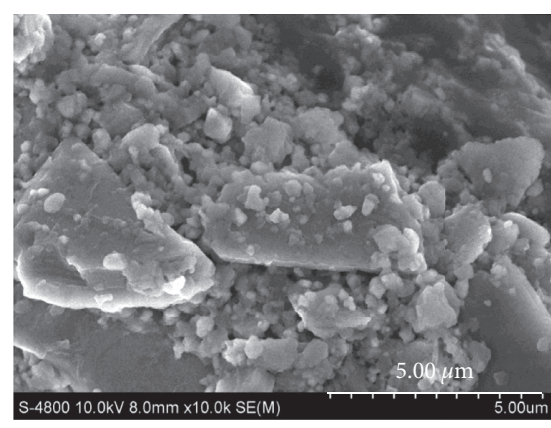

(a)

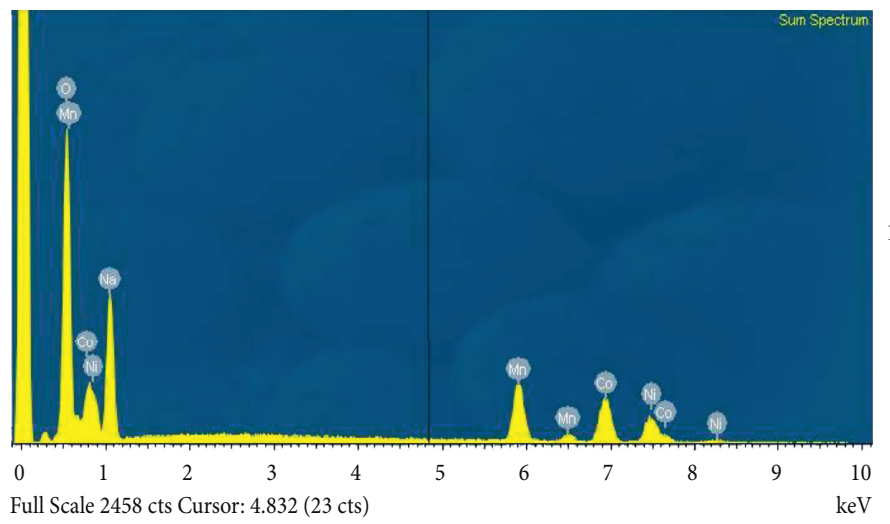

(d)

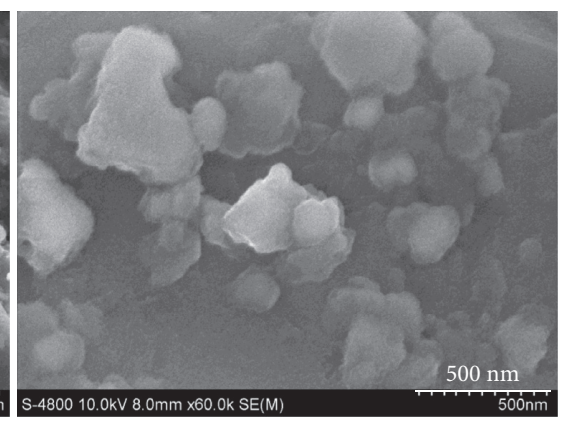

(b)

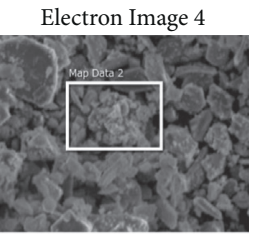

$\widetilde{10 \mu \mathrm{m}}$

(e)

$\mathrm{Mn} \mathrm{K} \alpha 1$

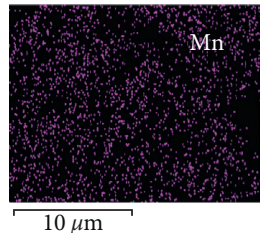

(h)

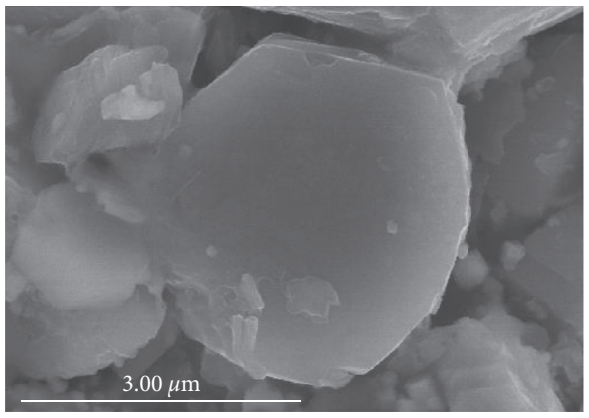

(c)

Na K $\alpha 1 \_2$

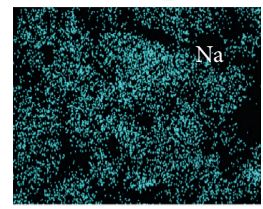

$10 \mu \mathrm{m}$

Co K $\alpha 1$

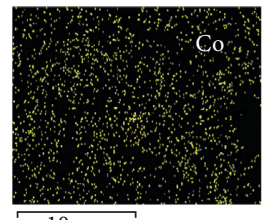

(i)

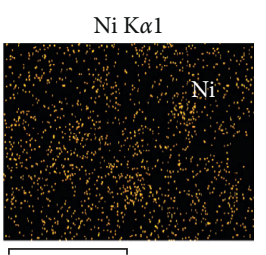

$10 \mu \mathrm{m}$

(g)

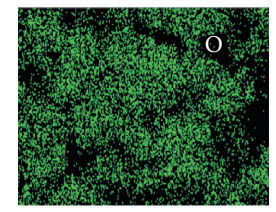

FIGURE 2: $(a-c)$ SEM images of the sample and $(d-j)$ the EDX spectrum showing the composition of various elements in the NaNMC sample.

individual phase at the beginning of charging. Generally, the P3-phase region exists until a voltage step occurred in the voltage profile where an intermediate P1-phase forms and then disappears, according to the solid solution behavior of sodium extraction in the first charging. Interestingly, the peaks belonging to the $\mathrm{P} 3$-phase located at $36.7^{\circ}, 38.0^{\circ}$, and $45.7^{\circ}$ instantly disappear, while the peaks belonging to the $\mathrm{P} 2$-phase remain in the voltage range $3.8-4.0 \mathrm{~V}$ than they 
TABLE 1: The composition of various elements in the NaNMC sample.

\begin{tabular}{lcccrr}
\hline & $\mathrm{Na}$ & $\mathrm{Mn}$ & $\mathrm{Ni}$ & $\mathrm{Co}$ & \\
\hline Weight percentage (\%) & 20.8 & 16.9 & 18.0 & 15.5 & 28.8 \\
Normalized ratio & 1.03 & 0.35 & 0.35 & 0.30 & 2.05 \\
\hline
\end{tabular}

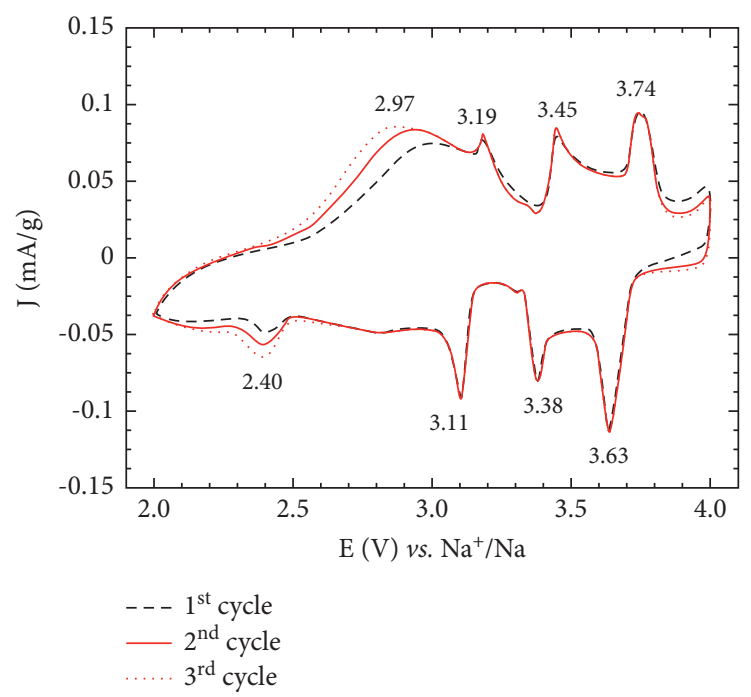

Figure 3: Cyclic voltammogram of the NaNMC cathode in the voltage range of $2.0-4.0 \mathrm{~V}$ at the scanning rate of $100 \mu \mathrm{V} \cdot \mathrm{s}^{-1}$.

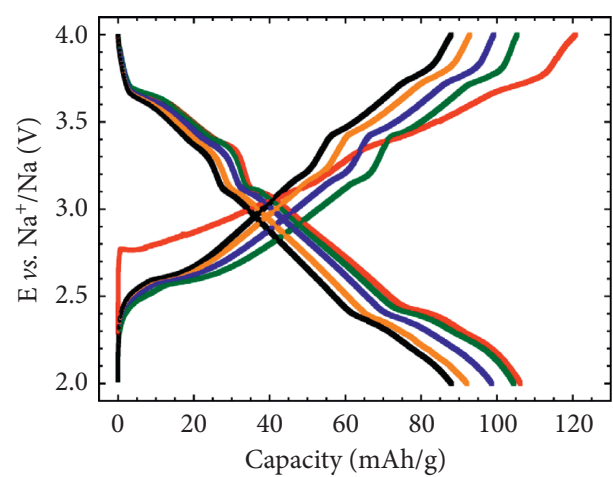
- Cycle 1
- Cycle 25
- Cycle 50

(a)

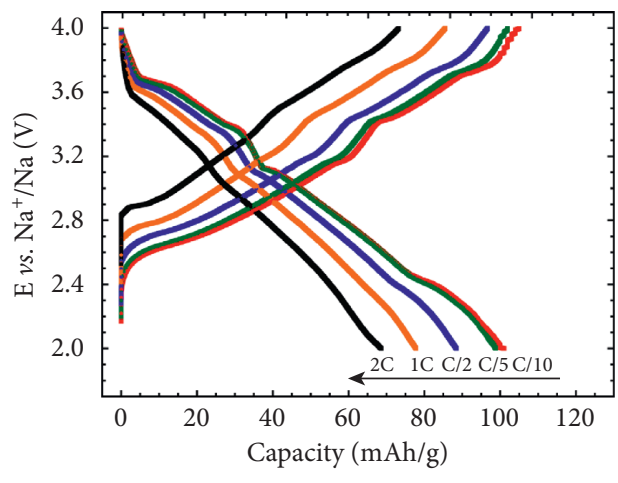

(c)

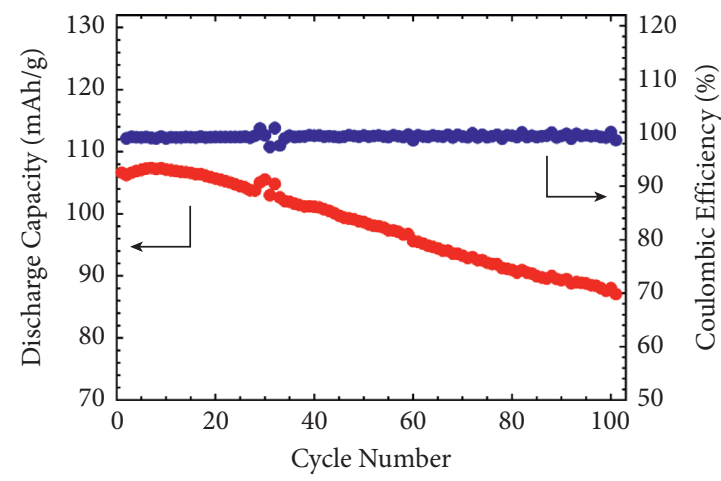

(b)

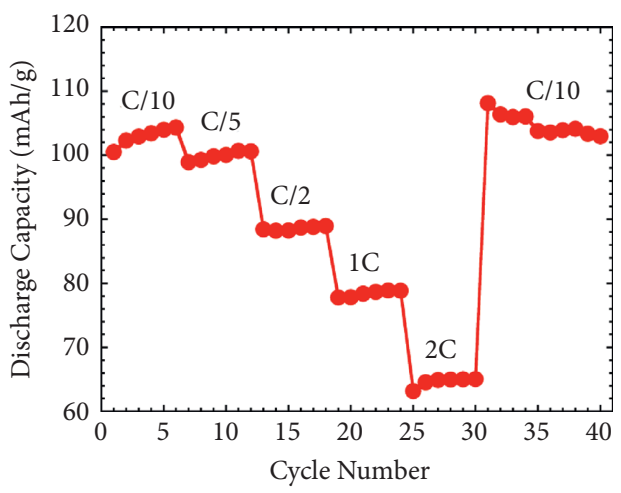

(d)

Figure 4: (a) Charge/discharge curves of the P2/P3-NaNMC electrode at a current density of C/10. (b) Discharge capacity and Coulombic efficiency versus cycle number for the electrode. (c) Voltage profile of material at various current densities. (d) The rate capability of the electrode. 


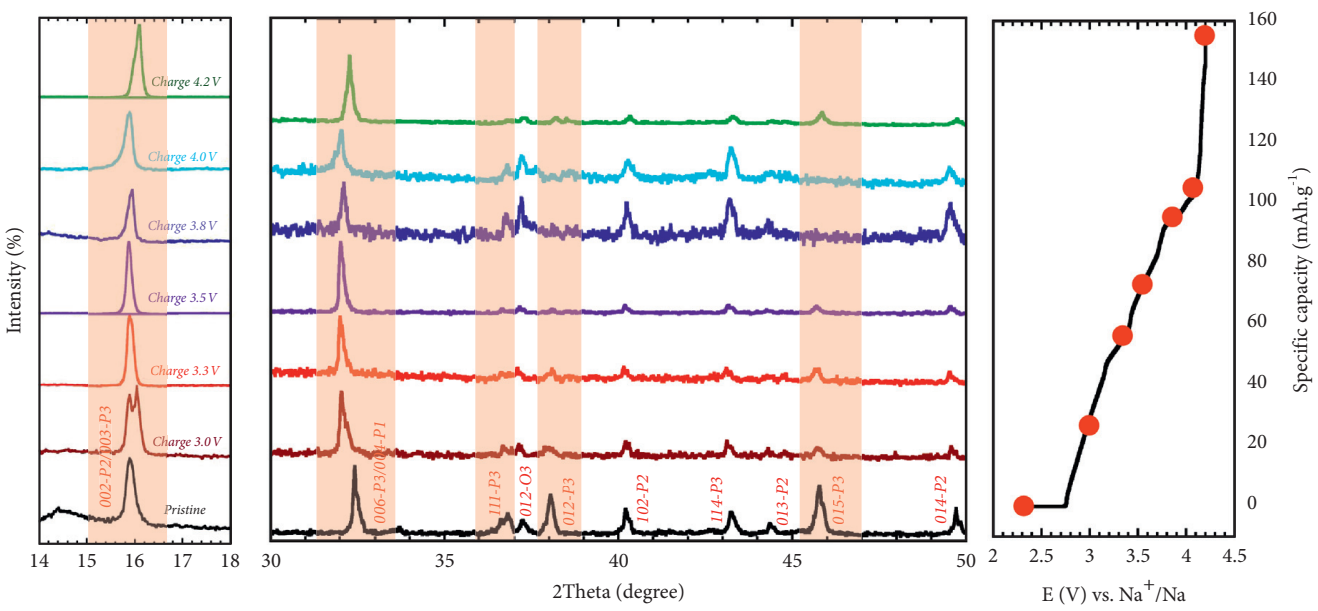

FIGURE 5: XRD patterns of the P2/P3-NaNMC electrode at various charge stages during the first charging.

appear when charged to $4.2 \mathrm{~V}$. The absence of peaks of the P3-phase could demonstrate a complex phase composition in the high-voltage region on charging. As could be seen, the peaks of the P2-phase remain during the charge process, so the phase transition of the material is governed by the P3phase. Previous studies demonstrated that a transition could be $\mathrm{P} 2 / \mathrm{P} 3$ to $\mathrm{P} 2 / \mathrm{P} 3 / \mathrm{OP} 4$ via a mix-phase intergrowth in the $3.8-4.2 \mathrm{~V}$ region [28, 29]. However, the slitting of peak located at $16^{\circ}$ is not observed event at a high stage of charge 4.2 V, which elicited that $\mathrm{P} 2-\mathrm{OP} 4$ phase transition probably be suppressed in the P3/P2 intergrowth NaNMC.

When the material was discharged to $2.0 \mathrm{~V}$, the new peaks of the O1-phase appeared that are mainly located at $16.29^{\circ}, 32.92^{\circ}, 36.45^{\circ}, 37.16^{\circ}$, and $43.18^{\circ}$ (shown in Figure 6). Therefore, the material structure has transformed from the $\mathrm{P} 2 / \mathrm{P} 3$ - to $\mathrm{P} 2 / \mathrm{O} 1$-phase and vice versa. The O1-phase could be an intermediated phase during phase transition from $\mathrm{O} 3$ to P3 of the NaNMC electrode [7,8]. It is noticeable that the peaks of the $\mathrm{P} 2$-phase remained during the charge process, indicating that the P2-phase does not exhibit phase transition.

3.4. Diffusion Coefficient of P2/P3-NaNMCMaterial. $\mathrm{Na}^{+}$ion diffusion coefficient $\left(\mathrm{D}_{\mathrm{Na}}\right)$ in both insertion and extraction processes was calculated by the GITT technique to evaluate the $\mathrm{Na}^{+}$ion diffusion kinetics inside the P2/P3-NaNMC. The cell was cycled twice at the same rate in a voltage range of 2.0-4.0 V before the GITT process. The diffusion coefficient in the solid electrode is the rate-determining process, and the transport of alkali ions in the electrode obeys Fick's second law; the chemical diffusion coefficients can be obtained by the following equation:

$$
\mathrm{D}_{\mathrm{Na}}=\frac{4}{\pi}\left(I_{o} \frac{V_{m}}{F S}\right)^{2}\left[\frac{\mathrm{d} E / \mathrm{d} x}{\mathrm{~d} E / \mathrm{d} t^{1 / 2}}\right]^{2},
$$

in which $I_{o}$ is the current $(A) ; V_{\mathrm{m}}$ is the molar volume of the electrode $\left(\mathrm{cm}^{3} \cdot \mathrm{mol}^{-1}\right) ; \quad F$ is the Faraday constant $\left(96485 \mathrm{C} \cdot \mathrm{mol}^{-1}\right) ; S$ is the electrode/electrolyte contact area $\left(S=1.13 \mathrm{~cm}^{2}\right) ; \mathrm{d} E / \mathrm{d} x$ is the slope of the coulometric titration curve, determined by plotting the steady-state voltages $E(V)$ measured after each titration step $x$; and $\mathrm{d} E / \mathrm{d} t^{1 / 2}$ is the slope of the linearized plot of the potential $E(V)$ versus $t^{1 / 2}(t$ is measured in seconds). GITT curves for the charge and discharge process describe the quasiequilibrium voltage values at each step of oxidation/reduction in voltage range 2.0-4.0 V. A detailed analysis on these two figures helps to define the value of $\mathrm{d} E / \mathrm{d} x$ and $\mathrm{d} E / \mathrm{d} t^{1 / 2}$ for the oxidation and reduction, as previously reported $[12,27]$.

Figure 7 presents the evolution of $\mathrm{D}_{\mathrm{Na}}{ }^{+}$during the charge and discharge process. Typically, $\mathrm{D}_{\mathrm{Na}}$ increases gradually from the beginning to the voltage jumping forming a peak of $8.14 \times 10^{-10} \mathrm{~cm}^{2} \cdot \mathrm{s}^{-1}$ at around $x=0.20$. The case could be explained as the extraction of sodium ions in the outer layer give more space for the inside sodium ions to move on charging; thus, the reverse trend is also seen in the discharging. The change of $\mathrm{D}_{\mathrm{Na}}{ }^{+}$on discharging could be divided by two regions: (i) the P-type region with high diffusion ability $(>2.5 \mathrm{~V})$ and (ii) the O-type region with low diffusion ability (the remaining region of the discharge curve). The $\mathrm{D}_{\mathrm{Na}}{ }^{+}$nearly retains the same value during the discharge to $x=0.22$ demonstrating a stability of sodium ion diffusion in $\mathrm{P} 3$-phase region. The value of $\mathrm{D}_{\mathrm{Na}}{ }^{+}$in this region is slightly higher than the value during the charge, but it drops suddenly from about $10^{-10} \mathrm{~cm}^{2} \cdot \mathrm{s}^{-1}$ to $10^{-11} \mathrm{~cm}^{2} \cdot \mathrm{s}^{-1}$ when the P3-phase undergoes phase transition in the plateaus. Thus, the change of $\mathrm{D}_{\mathrm{Na}}{ }^{+}$in discharge is in agreement with previous work which reported that the prismatic $\mathrm{Na}^{+}$ occupied site during sodium ion insertion/deinsertion is necessary for high-performance cathode materials [30] as low barrier for sodium ion to migrate.

Figures 8(a) and 8(b) display EIS spectra of the NaNMC electrode obtained during sodiation/desodiation depending on the number of sodium ions inserted/extracted.

Generally, the EIS spectra exhibit two semicircles; one is compressed and appears at high frequency whereas the other appears at low frequency. The first compressed semicircle could be divided by two processes including the resistance of the SEI layer and followed by charge transfer at the electrode/electrolyte interface [31]. Meanwhile, the presence of the second semicircle could be assumed to be 


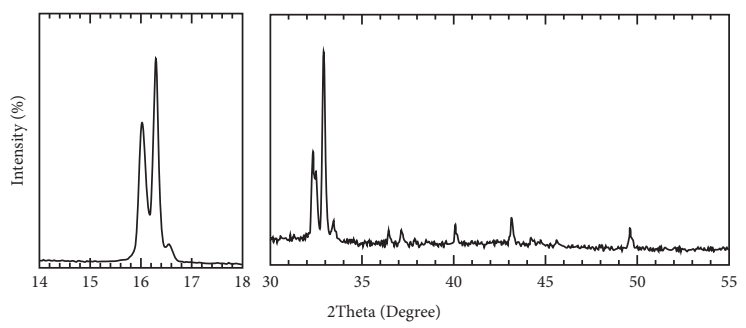

FIGURE 6: XRD patterns of the P2/P3-NaNMC electrode discharge to $2 \mathrm{~V}$.

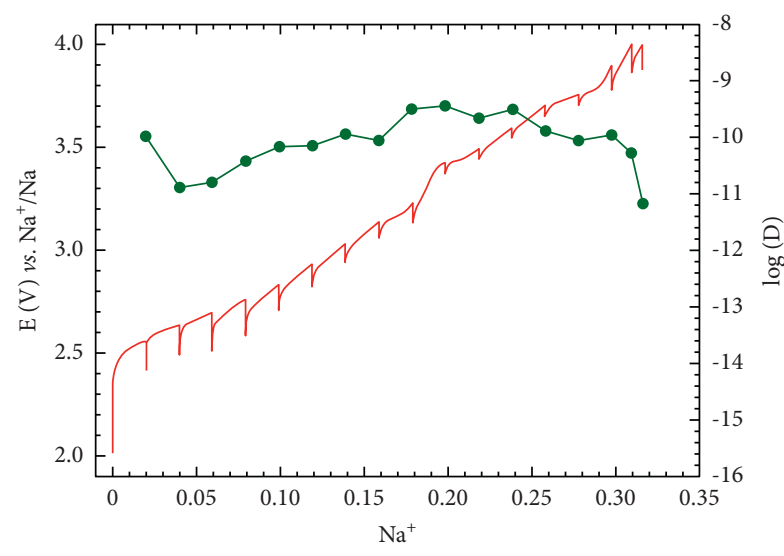

- E

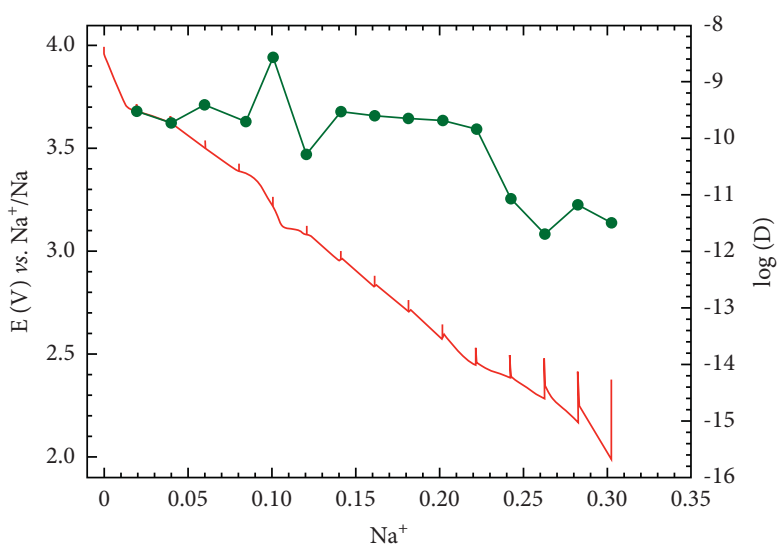

$\longrightarrow$
$\longrightarrow \log (D)$

(a)

(b)

FigURE 7: Titration curve and plot of the logarithm of diffusion coefficient $\mathrm{D}_{\mathrm{Na}}$ versus for the oxidation process (a) and the reduction process (b).

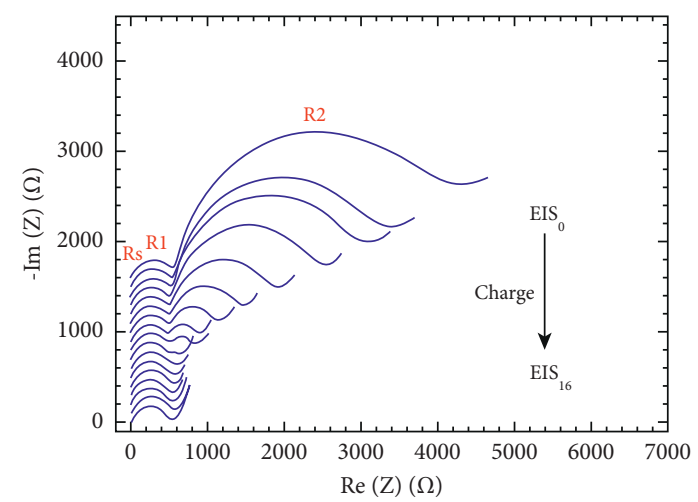

(a)

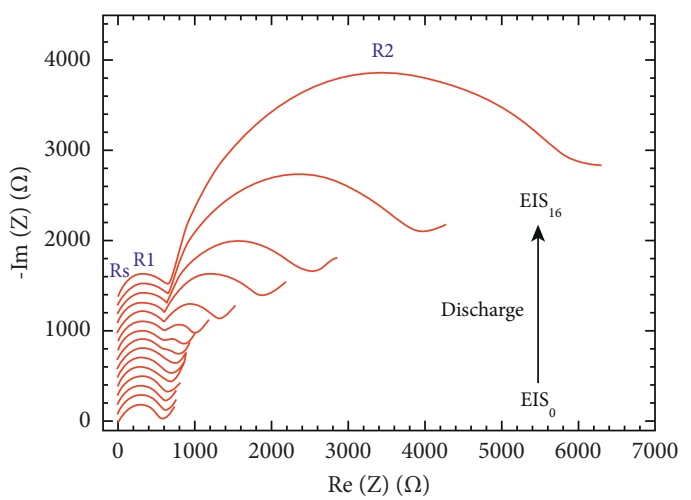

(b)

Figure 8: Continued. 


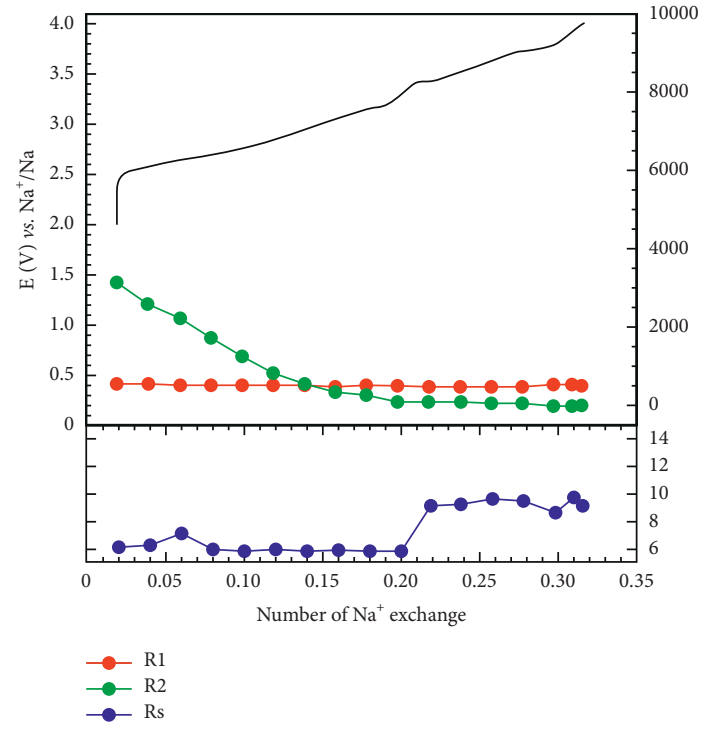

(c)

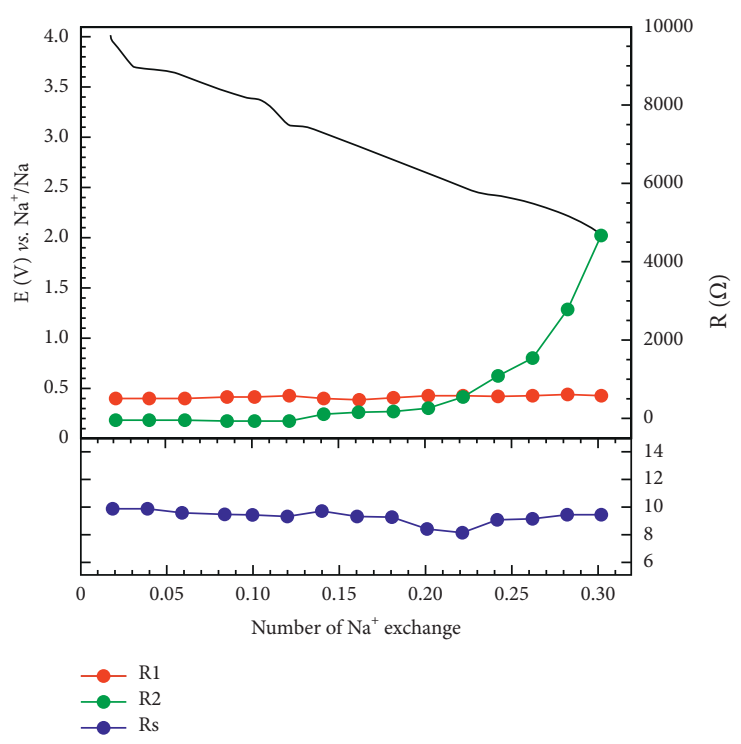

(d)

FIgURE 8: Nyquist plot of NaNMC cathode batteries in charging (a) and discharging (b). The evolution of semicircle resistances Rs, $R 1$, and $R 2$ in charging (c) and discharging (d).

the transportation and the charge transfer of $\mathrm{Na}^{+}$ion in the inhomogeneous structure. The second semicircle in case of $\mathrm{P} 2 / \mathrm{P} 3$ composite NaNMC is larger than that of P2/ O1/O3-NaNMC previously reported by our group [25] demonstrating the higher barrier of diffusion in the P-type phase than the P/O-type mixed phase. The second semicircle tends to decrease gradually on charge and then disappears at $3.1 \mathrm{~V}$; thus, the EIS spectra collected from this voltage show one semicircle only. The tendency of the second semicircle quite matches to the movement of the boundary O1/P3 and the formation of the P3-phase at higher voltage. As the potential increased on charging, the gradient concentration decreased gradually and the phase boundary disappeared, along with the unique P3 structure form after phase transition; thus, a uniform distribution of $\mathrm{Na}^{+}$ions in the bulk was obtained [25]. The tendency of the second semicircle is opposite during charging and discharging revealing the reversible nature of phase transition.

In general, EIS spectra could be fitted using an equivalent model suggested [31]. Figures $8(\mathrm{c})$ and $8(\mathrm{~d})$ show the change of impedance related to the charge/discharge stage. As mentioned, $R 1$ resistance remains relatively stable at around $500 \Omega$ in both charging and discharging. Meanwhile, the $R 2$ resistance decreases gradually on charging and vice versa on discharging due to the evolution of the biphase boundary inside the particle and/or the change of phase composition.

\section{Conclusions}

Double-phase P2/P3 intergrowth $\mathrm{NaNi}_{1 / 3} \mathrm{Mn}_{1 / 3} \mathrm{Co}_{1 / 3} \mathrm{O}_{2}$ (NaNMC) synthesized combined sol-gel and solid-state methods exhibited relatively good performance in a sodium half-cell. CV curves and charge-discharge profiles showed the characteristic shape like that of single-phase NaNMC. A high capacity of $107 \mathrm{mAh} \cdot \mathrm{g}^{-1}$ at $\mathrm{C} / 10$ and a capacity retention of $82.2 \%$ after 100 cycles were obtained. GITT and EIS were combined to explore the relation between the phase transition and sodium diffusion as well as the resistance properties of the material. The diffusion coefficient was in the range of $10^{-10}-10^{-11} \mathrm{~cm}^{2} \cdot \mathrm{s}^{-1}$ during charging and changed slightly with the same range during discharging. EIS spectra showed that a second semicircle appeared at a lower voltage whereas the two-phase equilibrium $\mathrm{O} 1 \leftrightarrow \mathrm{P} 3$ existed. The evolution of diffusion coefficient and charge transfer resistance is comparable with the structural transitions caused by the $\mathrm{Na}^{+}$insertion/deinsertion.

\section{Data Availability}

The data used to support the findings of this study are available from the corresponding author upon request.

\section{Conflicts of Interest}

The authors declare no conflicts of interest.

\section{Acknowledgments}

This research was funded by Viet Nam National University Ho Chi Minh City (VNUHCM) under grant CODE B202018-06.

\section{References}

[1] V. Etacheri, R. Marom, R. Elazari, G. Salitra, and D. Aurbach, "Challenges in the development of advanced Li-ion batteries: a review," Energy \& Environmental Science, vol. 4, no. 9, pp. 3243-3262, 2011. 
[2] D. Lin, Y. Liu, and Y. Cui, "Reviving the lithium metal anode for high-energy batteries," Nature Nanotechnology, vol. 12, no. 3, pp. 194-206, 2017.

[3] H. Hou, X. Qiu, W. Wei, Y. Zhang, and X. Ji, "Carbon anode materials for advanced sodium-ion batteries," Advanced Energy Materialsr.vol. 7, no. 24, pp. 1-30, 2017.

[4] H. Pan, Y.-S. Hu, and L. Chen, "Room-temperature stationary sodium-ion batteries for large-scale electric energy storage," Energy \& Environmental Science, vol. 6, no. 8, pp. 2338-2360, 2013.

[5] S. Y. Hong, Y. Kim, Y. Park, A. Choi, N.-S. Choi, and K. T. Lee, "Charge carriers in rechargeable batteries: $\mathrm{Na}$ ions vs. Li ions," Energy \& Environmental Science, vol. 6, no. 7, pp. 2067-2081, 2013.

[6] L. Wang, Y.-G. Sun, L.-L. Hu et al., "Copper-substituted $\mathrm{Na}_{0.67} \mathrm{Ni}_{0.3-\mathrm{x}} \mathrm{Cu}_{\mathrm{x}} \mathrm{Mn}_{0.7} \mathrm{O}_{2}$ cathode materials for sodium-ion batteries with suppressed P2-O2 phase transition," Journal of Materials Chemistry, vol. 5, no. 18, pp. 8752-8761, 2017.

[7] E. de la Llave, P. K. Nayak, E. Levi et al., "Electrochemical performance of $\mathrm{Na}_{0.6}\left[\mathrm{Li}_{0.2} \mathrm{Ni}_{0.2} \mathrm{Mn}_{0.6}\right] \mathrm{O}_{2}$ cathodes with highworking average voltage for Na-ion batteries," Journal of Materials Chemistry, vol. 5, no. 12, pp. 5858-5864, 2017.

[8] D. H. Lee, J. Xu, and Y. S. Meng, "An advanced cathode for Na-ion batteries with high rate and excellent structural stability," Physical Chemistry Chemical Physics, vol. 15, no. 9, pp. 3304-3312, 2013.

[9] S.-W. Kim, D.-H. Seo, X. Ma, G. Ceder, and K. Kang, "Electrode materials for rechargeable sodium-ion batteries: potential alternatives to current lithium-ion batteries," Advanced Energy Materials, vol. 2, no. 7, pp. 710-721, 2012.

[10] Y.-E. Zhu, X. Qi, X. Chen et al., "A P2- $\mathrm{Na}_{0.67} \mathrm{Co}_{0.5} \mathrm{Mn}_{0.5} \mathrm{O}_{2}$ cathode material with excellent rate capability and cycling stability for sodium ion batteries," Journal of Materials Chemistry, vol. 4, no. 28, pp. 11103-11109, 2016.

[11] P. Wang, Y. You, Y. Yin, and Y. Guo, "Layered oxide cathodes for sodium-ion batteries: phase transition, air stability, and performance," Advanced Energy Materials, vol. 8, no. 8, Article ID 1701912, 2018.

[12] C. Delmas, C. Fouassier, and P. Hagenmuller, "Structural classification and properties of the layered oxides," Physica $B+C$, vol. 99, no. 1-4, pp. 81-85, 1980 .

[13] L. Yang, S. Luo, X. Liu, W. Mu, and F. Teng, "Cu-doped layered P2-type $\mathrm{Na}_{0.67} \mathrm{Ni}_{0.33-\mathrm{x}} \mathrm{Cu}_{\mathrm{x}} \mathrm{Mn}_{0.67} \mathrm{O}_{2}$ cathode electrode material with enhanced electrochemical performance for sodium-ion batteries," Chemical Engineering Journal, vol. 404, Article ID 126578, 2021.

[14] H.-b. Huang, S.-h. Luo, C.-l. Liu et al., "Double-carbon coated $\mathrm{Na}_{3} \mathrm{~V}_{2}\left(\mathrm{PO}_{4}\right)_{3}$ as a superior cathode material for Na-ion batteries," Applied Surface Science, vol. 487, pp. 1159-1166, 2019.

[15] Q. Huang, S. Xu, L. Xiao et al., "Improving the electrochemical properties of the manganese-based P3 phase by multiphasic intergrowth," Inorganic Chemistry, vol. 57, no. 24, pp. 15584-15591, 2018.

[16] H. Van Nguyen, M. Le Nguyen, M. Van Tran, N. T. Tran, and P. M. L. Le, "Performance of full-cell Na-ion with $\mathrm{NaNi}_{1}$ / ${ }_{3} \mathrm{Mn}_{1 / 3} \mathrm{Co}_{1 / 3} \mathrm{O}_{2}$ cathode material and different carbonatebased electrolytes," Science and Technology Development Journal-Natural Science, vol. 4, no. 4, pp. 744-752, 2020.

[17] M. Sathiya, K. Hemalatha, K. Ramesha, J.-M. Tarascon, and A. S. Prakash, "Synthesis, structure, and electrochemical properties of the layered sodium insertion cathode material: $\mathrm{NaNi}_{1 / 3} \mathrm{Mn}_{1 / 3} \mathrm{Co}_{1 / 3} \mathrm{O}_{2}$," Chemistry of Materials, vol. 24, no. 10, pp. 1846-1853, 2012.
[18] M. V. T. V. H. Nguyễn, T. T. L. Nguyễn, L. T. N. Huỳnh, and M. L. P. Lê, "Tính chất điện hóa của vật liệu $\mathrm{NaNi}_{1 / 3} \mathrm{Mn}_{1 /}$ ${ }_{3} \mathrm{Co}_{1 / 3} \mathrm{O}_{2}$ tổng hợp bằng phương pháp sol-gel," Tạp chí hóa hoc, vol. 55, pp. 105-109, 2017.

[19] V. S. Rangasamy, S. Thayumanasundaram, J.-P. Locquet, and J. W. Seo, "Influence of sol-gel precursors on the electrochemical performance of $\mathrm{NaMn}_{0.33} \mathrm{Ni}_{0.33} \mathrm{Co}_{0.33} \mathrm{O}_{2}$ positive electrode for sodium-ion battery," Ionics, vol. 23, no. 3, pp. 645-653, 2017.

[20] S. Bao, S.-h. Luo, Z.-y. Wang, S.-x. Yan, Q. Wang, and J.-y. Li, "Novel P2-type concentration-gradient $\mathrm{Na}_{0.67} \mathrm{Ni}_{0.167} \mathrm{Co}_{0.167} \mathrm{Mn}_{0.67} \mathrm{O}_{2}$ modified by Mn-rich surface as cathode material for sodium ion batteries," Journal of Power Sources, vol. 396, pp. 404-411, 2018.

[21] J. Zhang, S.-H. Luo, L.-L. Sui, Y.-Y. Sun, and Y.-H. Niu, "Coprecipitation assisted hydrothermal method to synthesize $\mathrm{Li}_{0.9} \mathrm{Na}_{0.1} \mathrm{Mn}_{0.9} \mathrm{Ni}_{0.1} \mathrm{PO}_{4} / \mathrm{C}$ nanocomposite as cathode for lithium ion battery," Journal of Alloys and Compounds, vol. 768, pp. 991-994, 2018.

[22] S. Bao, S. Luo, Z. Wang et al., "The critical role of sodium content on structure, morphology and electrochemical performance of layered P2-type $\mathrm{Na}_{\mathrm{x}} \mathrm{Ni}_{0.167} \mathrm{Co}_{0.167} \mathrm{Mn}_{0.67} \mathrm{O}_{2}$ for sodium ion batteries," Journal of Power Sources, vol. 362, pp. 323-331, 2017.

[23] I. Hasa, D. Buchholz, S. Passerini, B. Scrosati, and J. Hassoun, "High performance $\mathrm{Na}_{0.5}\left[\mathrm{Ni}_{0.23} \mathrm{Fe}_{0.13} \mathrm{Mn}_{0.63}\right] \mathrm{O}_{2}$ cathode for sodium-ion batteries," Advanced Energy Materials, vol. 4, no. 15, Article ID 1400083, 2014.

[24] G.-L. Xu, R. Amine, Y.-F. Xu et al., "Insights into the structural effects of layered cathode materials for high voltage sodium-ion batteries," Energy \& Environmental Science, vol. 10, no. 7, pp. 1677-1693, 2017.

[25] H. Van Nguyen, H. T. N. Nguyen, N. L. T. Huynh, A. L. B. Phan, M. Van Tran, and P. M. L. Le, "A study of the electrochemical kinetics of sodium intercalation in $\mathrm{P} 2 / \mathrm{O} 1 /$ O3- $\mathrm{NaNi}_{1 / 3} \mathrm{Mn}_{1 / 3} \mathrm{Co}_{1 / 3} \mathrm{O}_{2}$," Journal of Solid State Electrochemistry, vol. 24, no. 1, pp. 57-67, 2020.

[26] Y.-N. Zhou, P.-F. Wang, Y.-B. Niu et al., "A P2/P3 composite layered cathode for high-performance Na-ion full batteries," Nanomaterials and Energy, vol. 55, pp. 143-150, 2019.

[27] Y. Wang, G. Hu, Z. Peng et al., "Influence of Li substitution on the structure and electrochemical performance of P2-type $\mathrm{Na}_{0.67} \mathrm{Ni}_{0.2} \mathrm{Fe}_{0.15} \mathrm{Mn}_{0.65} \mathrm{O}_{2}$ cathode materials for sodium ion batteries," Journal of Power Sources, vol. 396, pp. 639-647, 2018.

[28] J.-Y. Hwang, C. S. Yoon, I. Belharouak, and Y.-K. Sun, "A comprehensive study of the role of transition metals in O3type layered $\mathrm{Na}\left[\mathrm{Ni}_{\mathrm{x}} \mathrm{Co}_{\mathrm{y}} \mathrm{Mn}_{\mathrm{z}}\right] \mathrm{O}_{2}(\mathrm{x}=1 / 3,0.5,0.6$, and 0.8$)$ cathodes for sodium-ion batteries," Journal of Materials Chemistry, vol. 4, no. 46, pp. 17952-17959, 2016.

[29] X. Chen, X. Zhou, M. Hu et al., "Stable layered P3/P2 $\mathrm{Na}_{0.66} \mathrm{Co}_{0.5} \mathrm{Mn}_{0.5} \mathrm{O}_{2}$ cathode materials for sodium-ion batteries," Journal of Materials Chemistry, vol. 3, no. 41, pp. 20708-20714, 2015.

[30] H. Yao, P. Wang, Y. Wang, and Y. Guo, "Excellent comprehensive performance of Na-based layered oxide benefiting from the synergetic contributions of multimetal ions," $A d-$ vanced Energy Materials, vol. 7, no. 15, Article ID 1700189, 2017.

[31] W. Choi, H.-C. Shin, J. M. Kim, J.-Y. Choi, and W.-S. Yoon, "Modeling and applications of electrochemical impedance spectroscopy (EIS) for lithium-ion batteries," Journal of Electrochemical Science and Technology, vol. 11, no. 1, pp. 1-13, 2020. 